\title{
Integrated Education: Internalizing Socialist Core Values and Cultivating Positive Psychological Quality
}

\author{
Lijuan Feng *, Pingfan Zhang \\ College of Educational Science and Technology, \\ Northwest Minzu University, \\ Lanzhou, China, 730124
}

\begin{abstract}
Socialist core values are the spiritual guidance and value guidance of college students, and positive psychological quality is the main content for the construction of college students' harmonious mentality. Internalizing socialist core values is closely related to cultivating positive psychological quality. From the perspective of cognitive dissonance theory and attribution need theory, this work found out the key factors of their integrated education. Based on the current situation of ethnic colleges and universities in northwest region, this work aimed to achieve the coordinated development and integrated education of internalizing socialist core values and cultivating positive psychological quality through four approaches: increasing cognitive experience by relying on traditional culture, strengthening emotional experience by loving care, setting an example to guide the construction of will and promoting action experience by learning and practicing.
\end{abstract}

Keywords-Socialist core values; Positive psychological quality; Integrated education

\section{INTRODUCTION}

Socialist core values are the core of the socialist core value system, which embodies the essential requirements of socialist ideology. Including the three levels of state, society and individual, the 18th National Congress summarized the socialist core values as follows (24 words): prosperity, democracy, civilization and harmony are the goals of building a modern socialist country; freedom, equality, justice and the rule of law are vivid expressions of a better society; patriotism, dedication, integrity and friendship are the moral standards of individual citizens. In the report of the 19th National Congress, President $\mathrm{Xi}$ Jinping emphasized again that it is necessary to cultivate and practice the socialist core values, integrate them into all aspects of social development, and transform them into people's emotional identity and behavior habits. At present, the outlook on life and values of college students have not yet been formed steadily, and they have great plasticity and instability. Especially, students of ethnic universities are influenced by traditional customs, multiculturalism and even by the malicious value intervention of individual improper religious forces, which can easily lead to contradictions and conflicts in students' inner cognitive level. The level of confusion and choice not only hinders the internalization of socialist core values, but also becomes a difficult problem of ideological and political education in colleges and universities. Therefore, promoting the internalization of socialist core values and cultivating students' positive psychological quality has become an urgent problem to be solved in the new era of education.

\section{QUESTIONS RAISED}

Socialist core values are internalized in mind and externalized in action. Some scholars believe that its psychological mechanism includes four continuous psychological processes: cognition, conformity, assimilation and adaptation, which involves the transformation of cognitive structure at the individual psychological level [1], This is in accordance with the process of cultivating college students' healthy personality and positive psychological quality, which is one of the goals of mental health training in colleges and universities [2]. Psychological quality is based on physiological conditions, which converts external stimuli into stable, basic, derivative and developmental functions, and it is closely related to human adaptive behavior and creative behavior [3]. The word "positive" implies positive, developmental, optimistic and enterprising aspects. Cultivating positive psychological quality is an important part of harmonious mentality construction.

Internalizing socialist core values is closely related to cultivating positive psychological quality. First of all, the training goals are consistent, at the group level, they advocate creating a harmonious atmosphere and building a better society. At the individual level, they all want to cultivate people who develop in all-round and harmonious development [4]. Secondly, the dialectical unity of the two is mainly manifested in the following aspects: on the one hand, under the guidance of the socialist core values, college students can effectively resolve the differences in ideas, correct bad cognition, achieve a high degree of ideological harmony and form positive psychological quality; on the other hand, the individual with positive psychological quality is in a state of openness and tolerance, positive optimism and peace and closeness, which is also beneficial to the cognition and internalization of the socialist core values.

The internalization of college students' socialist core values and the cultivation of positive psychological quality are in one continuous line. Therefore, on the basis of the correlation between the two, this work explored the theoretical support of integrated education, and found out the key factors influencing the integration of the two. This work also combined the origin 
characteristics, national characteristics and cultural atmosphere of ethnic colleges and universities in northwest region, explored the new path, new method and new mode for the organic combination of the two, and guided ethnic college students to shape a harmonious and sunny positive mentality under the guidance of the socialist core values.

\section{THE THEORETICAL BASIS OF INTEGRATED EDUCATION}

\section{A. Cognitive dissonance theory}

Cognitive dissonance theory was originally put forward by Leon Festinger. He believes that everyone has his own cognitive system. When there is disharmony among the cognitive elements of the cognitive system, the individual will have cognitive conflict. With the negative emotional experience such as anxiety, tension, unpleasant, stress conflict will urge the individual to make some changes to re-achieve psychological balance and restore cognitive coordination [5]. In the inheritance and development of cognitive dissonance theory, Aronson puts forward that people believe that they are honest and kind, but they often encounter contradictory information in real life, or make immoral acts for some self-interest reasons, which conflict with the self-image of good and decent, inconsistent knowledge and behavior, and produce cognitive dissonance [6].

The ideological and behavioral orientation guided by socialist core values is consistent with the Confucian traditional culture that people believe their human nature is good, and with the moral education that individuals receive from childhood. Individuals' internalization of socialist core values enables them to have criteria and benchmarks for judging things, coordinating actions and choosing interests. In the process of growth, it will produce a positive cycle of cooperative work system with individual psychological and behavioral patterns. When people internalize socialist core values in the mind and externalize them in the form, they are in a state of self-harmony, unity of knowledge and action, and cognitive coordination. The coordinated psychological state will provide rich spiritual soil for the cultivation of positive psychological quality. When the individual's decisions and actions do not conform to the traditional culture and socialist core values, through brain perception, there will be a conflict between the two cognitive elements of "bad behavior" and "I am kind and honest", and then there will be conflicting and nervous psychological feelings. If the dissonance event content is more important to oneself, then the degree of inconsistency perceived by the individual is greater [7]. Individuals who are often in a state of contradiction and conflict often have deviant behavior accompanied by serious emotional disorders such as anxiety and depression, which is not conducive to the formation of positive psychological quality.

Cognitive dissonance is the driving force of individual cognitive reconstruction. There are three ways to solve cognitive dissonance: firstly, it is necessary to change attitudes, resolve differences of ideas and correct bad perceptions; secondly, it is necessary to change wrong behaviors to conform to good perceptions; thirdly, it is necessary to add new cognitive elements to find out the differences between positive needs and desires behind negative behaviors, and neutralize the difference between cognitive elements, so as to gradually translate negative behaviors and comply with existing benign cognition. Only individuals who are in the state of cognitive coordination can forge a positive mental attitude and sunshine psychology, raise the psychological quality level, reasonably handle the contradiction and conflict, truly internalize the socialist core values and practice knowledge in practice.

\section{B. Attribution need theory}

Maslow, a humanistic psychologist, puts forward the need hierarchy theory that people have five basic needs, from low to high, which are in turn the needs of physiology, security, love and attribution, respect and self-realization. Among them, attribution refers to an internal relationship between an individual and its subordinate group, which is the delimitation, identification and maintenance of a particular group and its subordinate relationship by an individual [8]. The sense of belonging is a kind of psychological experience that an individual belongs to himself. It emphasizes the individual's self-perception and is the feeling that an individual is accepted and recognized [9]. Man is the sum of all social relations. When he is in social relations, he always wants to be a member of the social group and get acceptance, approval and mutual support from other members.

Previous works have shown that the sense of belonging to the group will have a significant impact on individual mental health [10]. Some researchers have found that peer relationships in the dimension of belonging can affect the mental health level of individuals [11]. When people experience a sense of belonging, they will be healthier and happier; on the contrary, they lack a sense of belonging, and they suffer from exclusion and social isolation, which results in negative emotional experiences such as anxiety, depression and anger [12]. Thus, lack of belonging will affect the establishment of individuals' positive psychological quality, such as social and group disapproval, self-closure, personality isolation, lack of positive beliefs, etc.

Internalizing socialist core values will help to improve the level of individual belonging, which is conducive to cultivating students' positive psychological quality. Based on the excellent traditional culture of China, the socialist core values contain the social virtues that have been widely spread since ancient times, and are generally recognized by the whole society. The internalization of socialist core values is to transform the concept of beauty and harmony in culture into one's own thought guidance and action guide, and form one's own individual values. When individual values are in line with socialist core values, they will identify with social culture and social groups at the ideological level, and show good behavior in line with the requirements and expectations of the mainstream positive values in society at the practical level. Then they will inevitably enhance the sense of belonging to social groups at both the ideological and practical levels. When individual thoughts and behaviors do not conform to the socialist core values, they will be alienated from social culture and social groups, including peer exclusion, lack of social support and blocked behavior, which not only reduces the sense of belonging, but also brings psychological trauma experience, emotional loss and breaks cognitive coordination due to rigid peer relationship. Therefore, the sense of belonging is also an important factor to promote the internalization of socialist core 
values and the cultivation of positive psychological quality. Strengthening the individuals' sense of belonging is the keyway for their integrated education.

\section{The PATH AND STRATEgy OF INTEGRATED EDUCATION}

Promoting individual cognitive coordination and increasing the sense of belonging will promote the internalization of individual socialist core values and the cultivation of positive psychological quality at the same time. Therefore, this work changed the propaganda mode of scientific socialist ideology under the previous policy guidance, combined the source characteristics and cultural atmosphere of the national colleges and universities in the northwest region, and fully explored the core factors affecting the synergy between the two. Based on the four levels of knowledge, affection, intention and action, this work constructed the communication idea of socialist core values and the cultivation path of positive psychological quality, transformed the authoritative indoctrination into the required growth, and improved the psychological quality level of college students.

\section{A. Relying on traditional culture to increase cognitive experience and promote cognitive coordination}

Excellent Chinese traditional culture has created spiritual soil for the development of Chinese children. Values are the core of culture, and culture is the basis of carrying values, and culture always affects people's way of thought and behavior in a certain mode and subtly [13]. Relying on the excellent traditional culture of Chinese, it is necessary to increase the individual's perception and identity of truth, goodness and beauty in traditional culture, and then grasp the connotation requirements of socialist core values, make positive behaviors in line with social expectations, achieve cognitive coordination and promote mental health development.

On the one hand, although the students of ethnic colleges and universities have distinct national characteristics, influenced by their region and national culture, they also have certain national psychology, but the respect and implementation of Chinese traditional culture by different nationalities go hand in hand. Therefore, ethnic colleges and universities can increase the proportion of traditional cultural public elective courses, artificially promote students' insight and understanding of Chinese traditional culture, ideas and values, and promote their consistent understanding with the connotation of socialist core values at the cognitive level. It provides a rich understanding of soil and thought precipitation for the unification and coordination of the two principles, and indirectly promotes individual psychological harmony. Secondly, the ethnic colleges and universities broaden and deepen the connotation and content of mental health education curriculum, and avoid narrow personality-oriented understanding of individual social behavior. Starting from the theory of social influence, they seek for the promotion and restraint of social culture, social politics, social personality and other elements on individual behavior. It is of great significance to help students to understand the harmonious psychological construction more deeply and to coordinate the traditional Chinese culture with the core values of socialism. Thirdly, with the construction of diversified campus culture as the container of spiritual orientation, campus cultural activities in ethnic colleges and universities can not simply be formalized and dazzling. It is a spiritual and emotional expression that carries all students' knowledge of society, culture, and human beings. "the way of the great learning involves manifesting virtue, loving the people, and abiding by the highest good". The shaping and guidance of moral character, especially the core moral character in socialist core values, from "individual morality" to "group morality", then to "social morality" and "national morality", are linked in a continuous line. Therefore, ethnic colleges and universities should make full use of the form of cultural activities, and slowly inject the shaping of moral character and values into the students' hearts, so as to help each individual make correct value judgment and behavior choice, and achieve cognitive coordination.

\section{$B$. The care of love strengthens emotional experience and creates an atmosphere of belonging}

Love is the core of emotion, and the care of love is an important aspect of personal belonging [14]. In campus life, peer relationship and teacher-student relationship will affect students belonging to the group, enhance their humanistic care for students, give students the feeling of love and create an atmosphere of belonging.

Firstly, teachers' love should be used to nourish students' hearts. Humanistic psychology advocates people-centered and teachers as facilitators. The necessary quality is to fully trust the students' development potential, and treat students in good faith and deeply understand the students [15]. The teacher-student relationship without emotional input can not touch the inner world of students and the barriers of mutual relationship, which not only reduces the students' sense of belonging to the school but also makes it easier to produce suspicion and negation of society and interpersonal relationship in the shaping of values. Love is also a demonstration. The action of love can teach students how to love others, respect and fully accept others, and understand others in a natural way. It is also a driving condition for the establishment of harmonious relationships. Therefore, the equal and harmonious teacher-student relationship and the support of teachers and friends are conducive to students to establish correct values and positive psychological quality. Secondly, psychological counseling should be used to improve emotional construction. Most of the students with psychological counseling needs have experienced frustration or traumatic experience during their growth and development, resulting in the wrong perception of life, society, interpersonal relationship and self, or psychological imbalance, emotional collapse or individual extreme behavior due to unsatisfactory emotional needs. Psychological counseling is one of the warmest ways to heal the relationship. Warm understanding, total respect and acceptance, proper positive attention and proper empathy are the most favorable weapons to help the parties to reconstruct their self-worth and are also supportive strategies to help the parties find problem-solving ability. The emotional flow in the consulting relationship is very important to reconstruct the allowed belonging for the parties. On the other hand, the positive and fluent emotional experience increases the possibility of parties' cognitive adjustment, strengthens the significance of the mainstream core values to action orientation, and promotes the construction of positive and healthy psychological quality. 


\section{Setting a role model to guide the construction of will and meet the need of belonging}

American psychologist Bandura's social learning theory holds that role models will play an alternative role of reinforcement. By observing the behavior and consequences of others, people will produce emotional identification and behavior imitation, so as to acquire new behavior. Thus, the impact of role models is enormous.

What is a role model? Role model is not only a symbol of characters but also an ideal personality. The essence of setting a role model is to help people internalize positive character through the concrete action and thought of the model. First of all, it is very important to find role models. College students are more open-minded and more inclusive of differences. The moral pioneers born in various fields of culture, science and technology, art and other fields can become the focus of students' attention. Through the propaganda of their advanced deeds, they can stimulate the positive emotional experience of college students, make them feel strong spiritual shock and infection in their hearts, and consciously and actively practice the content of socialist core values [13]. Second, based on the theory of belonging, individuals want to belong to the group and get the recognition of the group, then the role models in the surrounding group will be more likely to arouse people's emotional resonance and behavior imitation. When setting a role model, we can also focus on the role models of college students on campus. The similar experiences and ideological cognition between peers will make the true stories of role models hotter and more persuasive, and will certainly be more contagious and instructive than cold speeches. It is also easier to help the majority of students understand from the cognitive level, approach the emotional level, stick to and move at the level of will, and not only help individuals to seek the belonging needs of group culture and group morality, but also help individuals to complete the internalization of socialist core values and the shaping of positive psychological quality.

D. Promoting action experience and achieving the coordination between knowledge and action by knowledge, practice and action

Knowledge and action are an organic whole. Knowledge must imply action, and action must follow knowledge. "Action" plays the role of exciting interest, explanation and verification to "knowledge". Vivid and real social practice that closely combined with life experience can stimulate students' interest and emotional identity, enhance students' consciousness of subject participation, and make it easier to improve individual cognition and domestication.

First of all, college students are encouraged and organized to actively participate in all kinds of social practice activities, and not only in the winter and summer social practice in the countryside but also in the social practice of scientific research/technology leading output and social service for poverty alleviation and assistance. Rousseau's "natural consequence method" holds that children should be given free access to experience and cultivate their interest in practice so that they can keep "trial and error" in practice, and use the consequences of practice to correct wrong cognition and deepen correct cognition. Some researchers also believe that the main reason why Chinese adolescents do not have a high level of internalizing socialist core values is the lack of a sustained force that causes them to change from "knowledge" to "action" [17]. Practical activities are more vivid than theoretical education, and they are the extension of experiential teaching. In practical activities, students can not only hone their character and mentality but also profoundly understand the different behavioral consequences of different value choices. In experience and perception, they can find and consolidate correct criteria of value judgment, guide "action" by "knowledge", consolidate "knowledge" by "action", coordinate knowledge and action, and unify harmony. Second, practical action cannot be separated from social support. Social support can reduce dissonance behavior. The more social support a person receives, the stronger of belonging to be included and allowed, and the smaller the sense of dissonance [18]. Social support can be either interpersonal support or evaluation support, and college students' social practice activities take teamwork as the core. Interpersonal mutual help, compromise and adjustment, control and obedience all teach college students core values such as kindness to others and group priority. At the same time, it can also promote and convey positive values, increase the persuasion and appeal of public opinion, make the good behavior of individuals or groups recognized and supported by the society, and strengthen the cognitive orientation of practical action by selecting advanced persons or deeds.

\section{CONCLUSION}

The internalization of college students' socialist core values and the cultivation of positive psychological quality are highly connected, inherited and promoted to each other. Cognitive dissonance theory shows the internal harmony and unity of socialist core values and positive psychological quality, and belonging theory clarifies the internal motivation of group belonging for individual initiative to internalize the socialist core values system. Therefore, starting from the two key factors of cognitive coordination and belonging, based on the perception and recognition of truth, goodness and beauty from traditional culture education, the emotional support from teacher love care and psychological counseling, the spiritual infection and will building from role model, the change of knowledge and consolidate values from social practice, etc., it can really promote the internalization of individual socialist core values in mind and externalization in action. At the same time, it is necessary to achieve a high degree of unity and self-harmony, shape the sunshine mentality, and improve the level of students' positive psychological quality in knowledge, affection, intention and action.

\section{ACKNOWLEDGMENT}

Northwest Minzu University key projects of special funds for basic scientific research business for central colleges and universities: An Empirical Study on the Integration of Socialist Core Values and Mental Health Education in Universities for Nationalities (No. 31920170207).

Key project on propaganda and ideological work in universities of Gansu Province by Gansu Education Department and Gansu University Work Committee: Research on the Organic Integration of Socialist Core Values into the 
Psychological Crisis Intervention System of Minority College Students (No. XCSXZ201602).

\section{REFERENCES}

[1] Bai Qiang. Theoretical Review: Psychological Analysis of Internalizing College Students' Socialist Core Values [J]. Journal of Chongqing University (Social Science Edition), 2017 (02): 148.

[2] Meng Wanjin. On Positive Mental Health Education [J]. Educational Research, 2008 (05): 44.

[3] Zhang Dajun. On Human Psychological Quality [J]. Research on Psychology and Behavior, 2003 (02): 144.

[4] Chen Xinying. Try to Look at Our Socialist Core Values from the Perspective of Positive Psychology [J]. Science and Technology Information, 2013 (26): 251

[5] Leon Festinger. A Theory of Cognitive Dissonance. California: Stanford University Press, 1968, pp. 11-18.

[6] Li Lili. On E. Arenson's Cognitive Dissonance Theory [J]. Journal of Changchun University of Technology (Social Science Edition), 2008 (02): 27-28.

[7] Ma Defeng. Attitude Change: A Review of Festinger's Cognitive Dissonance Theory [J]. Journal of Huazhong University of Technology (Social Science Edition), 1999 (04): 80.

[8] Zhang Dajun. Educational Psychology [M]. Beijing: People's Education Press, 1999:242

[9] Wang Jin. Analysis of Belonging [J]. Journal of Xi'an Academy of Arts and Sciences (Social Sciences Edition), 2011 (04): 88.
[10] Ye Yiduo, Xiong Meng. The Effect of Group Belonging on the Mental Health for Children of Urban Migrant Workers and Its Internal Mechanism [J]. Journal of Fujian Normal University (Philosophy and Social Sciences Edition), 2013 (04): 151-152.

[11] Xu Kunying. A study on Middle School Students' Belonging and Its Relationship with Mental Health [D]. Chongqing: Southwest University, 2008.

[12] Barbara M. Newman, Brenda J. Lohman, Philip R. Newman. "Peer Group Membership and a Sense of Belonging: Their Relationship to Adolescent Behavior Problems”. Adolescence, Vol 42, No. 166, p. 241, Summer 2007.

[13] Yang Xiaozhe. Research on Socialist Core Values Education for College Students Based on Internalized Psychological Mechanism [D]. Shanghai East China University of Politics and Law, 2016.

[14] Qi Dunyu, Yu Jiangbo, Hou Aiqing. Application of the Need for Belonging and Love in Training [J]. Journal of Qiqihar University (Philosophy and Social Sciences Edition), 2011 (02): 157.

[15] Cao Shuzhen. On Rogers' View of Teachers and Students [J]. Foreign Education Research, 2000 (06): 5.

[16] Wu Jianyue. Enlightenment of "Integration of Knowledge and Action" Thought on School Moral Education Practice [J]. China Moral Education, 2018 (06): 26.

[17] Zhang Fandi, Fan Liguo. Promoting the Internalization of Adolescents' Socialist Core Values in Mental Health Education [J]. Journal of Shenyang University, 2011 (02): 41

[18] Xiang Guangqin, Some Thoughts on Cognitive Dissonance Theory [J]. Xuehai, 2010 (06): 53. 